\title{
High-dose Anabolic Implants Are Not All the Same for Growth and Carcass Traits of Feedlot Steers: A Meta-Analysis
}

\section{C.D. Reinhardt}

\section{Introduction}

The beneficial effects of anabolic implants with respect to feedlot performance and carcass weight are nearly unequivocal. Although individual prospective studies may have concluded that there are no significant differences between implant dosages, modern production economics demand that any differences, however small, must be gleaned if they are real. The objective of this study was to conduct a meta-analysis of existing data from peer-reviewed as well as industry sources to compare the effects of different doses of anabolic implants on feedlot performance and carcass traits of steers.

\section{Experimental Procedures}

Trials were queried from the Texas Tech North American Implant Database and the Journal of Animal Science database in August 2013 for the following key words: implant, carcass, and feedlot. Studies included in the present analysis were drawn from refereed journal publications, state extension research reports, and pharmaceutical company technical bulletins. The studies included in the meta-analysis reported data on some or all of the following variables: initial body weight, days of implant activity, number of pens or individual animals per treatment, average daily gain, feed:gain, dry matter intake, dressing percentage, hot carcass weight, yield grade, and percentage Choice or better.

Implant dosages of interest included negative controls, single estrogenic implants (20 mg estradiol benzoate $+200 \mathrm{mg}$ progesterone; $36 \mathrm{mg}$ zeranol; $72 \mathrm{mg}$ zeranol) and single implants of a combination of estrogen and trenbolone acetate (TBA). Within the meta-analysis, there was only one evaluation of each of the two single zeranol dosages, and no differences were determined between the three dosages of single estrogenic compounds utilized, so these were combined into a single treatment group (EST; Tables 1 and 2). The combination estrogen + TBA dosages included 24 mg estradiol-17ß and $120 \mathrm{mg}$ TBA (ET120), and the other included either $20 \mathrm{mg}$ estradiol-17ß + $200 \mathrm{mg}$ TBA or $28 \mathrm{mg}$ estradiol benzoate +200 TBA (ET200).

Two separate analyses were conducted using random effects models, with individual study considered a random effect, so that studies were properly weighted based on amount of within-study variation and sample size within each study. Dependent variables of interest included average daily gain, feed:gain, dry matter intake, dressing percentage, hot carcass weight, yield grade, percentage Choice or better, and marbling score. Effect sizes were calculated by subtracting (Comparison 1): treatment means for the non-implanted cattle from treatment means for implanted cattle, for each of the three treatment dosages; and (Comparison 2): treatment means for steers implanted with ET120 from those implanted with ET200. Data were imported from a spreadsheet into Comprehensive Meta Analysis v. 2.2.064 (Biostat, Inc., Englewood, NJ). 
Between-study variation, or heterogeneity, was determined using Cochran's Q-statistic, which determines the variability of effect sizes between studies:

$\mathrm{Q}=\sum \mathrm{w}_{\mathrm{i}}\left(\mathrm{T}_{\mathrm{i}}-\overline{\mathrm{T}}\right)^{2}$

$\mathrm{w}_{\mathrm{i}}=1 /\left(\mathrm{se}^{2}\right)$

where $T_{i}$ is the effect size within the $i^{\text {th }}$ study and $T$-bar is the mean of all the effect sizes across all studies in the analysis. In Comparison 1, the heterogeneity of effects of the implant dosage treatments (EST, ET120, and ET200 vs. non-implanted controls) was determined by comparing whether the difference between treatments was greater than what would be expected based on random error alone.

Publication bias is always a concern when conducting meta-analyses, and was especially concerning in the present analysis, which utilized a preponderance of data from non-refereed publications in the form of state extension research reports and company technical bulletins. Funnel plots were generated for each variable of interest to visually evaluate the possible existence of publication bias. Theoretically, standard error of the difference (SED) within studies, plotted against the treatment effect size within studies, should be equally and symmetrically distributed on either side of the mean effect size. Studies with smaller SED (greater weight in the meta-analysis) will appear nearer the top of the graph, and studies with greater SED (lesser weight) will appear nearer the bottom; in the absence of significant publication bias, the graph will have a symmetrical shape centered around a vertical line representing the mean effect size. The trim and fill method and Egger's linear regression were utilized to determine presence of publication bias.

Although the funnel plot for the analysis of average daily gain in Comparison 2 indicated a number of missing studies (Figure 1), the Trim and Fill procedure and Egger's linear regression indicated no significant effect of publication bias for any of the variables examined in either Comparison 1 or 2 . Effects were considered significant when the $P$-value fell below $P<0.05$.

\section{Results}

\section{Comparison 1}

There was no evidence of publication bias for any variables analyzed. Across all single implant treatments, implanting increased average daily gain, dry matter intake, dressing percentage, and hot carcass weight, and decreased feed:gain, percentage Choice and greater, and marbling score in steers $(P<0.05$; Table 3$)$ compared with negative controls; however, implant treatment had no effect on average calculated YG either across all treatments vs. negative controls $(P=0.42)$ or among implant treatments $(P=0.49)$.

Implanting with ET200 had a 61\%, 48\%, and 78\% greater influence on average daily gain, feed:gain, and hot carcass weight compared to EST alone $(P<0.05$; Table 3$)$, but ET120 was numerically intermediate and not different from either EST or ET200 for any of these variables. Implanting with ET200 also tended $(P=0.06)$ to reduce marbling score by 13 units vs. EST; ET120 was intermediate to EST and ET200 and not different from either. 


\section{Comparison 2}

Implanting with ET200 increased average daily gain by $0.046 \mathrm{lb}$ per day $(P=0.04)$, reduced $(P<0.01)$ feed:gain by 0.12 units, and reduced $(P<0.01)$ percentage of carcasses grading Choice or greater by $5.2 \%$ units compared with ET120. Marbling score $(P=0.33)$, hot carcass weight $(P=0.52)$, and yield grade $(P=0.22)$ did not differ between ET200 and ET120.

The effects of ET200 vs. ET120 on average daily gain, feed:gain, and percentage Choice and greater were regressed vs. the number of days the implant was active prior to harvest. No significant relationships were found between days of implant activity and average daily gain, feed:gain, or percentage Choice and greater $(P>0.05$; Table 4; Figure 4); however, the difference in percentage Choice and greater tended $(P=0.08)$ to increase by 1.1 percentage unit for each 100 days of implant activity prior to harvest.

\section{Implications}

Modern production practices and costs of production mandate that small improvements in productivity at the individual animal level, if real, must be investigated and captured.

Table 1. Number of individual treatment means used in the analysis of each response variable in 2 meta-analyses comparing the effects of estrogenic and combination estrogenic/androgenic implants to no implant (Comparison 1) or 2 combination estrogenic/androgenic implants (Comparison 2) in feedlot steers

\begin{tabular}{|c|c|c|c|c|}
\hline \multirow[b]{2}{*}{ Item } & \multicolumn{3}{|c|}{ Comparison $1^{1}$} & \multirow{2}{*}{$\frac{\text { Comparison } 2^{2}}{{\text { ET } 200^{5}}^{2}}$} \\
\hline & $\mathrm{EST}^{3}$ & ET120 & ET2005 & \\
\hline Average daily gain, $\mathrm{lb}$ & 16 & 28 & 27 & 34 \\
\hline Feed:gain & 16 & 25 & 26 & 32 \\
\hline Dry matter intake, lb/day & 15 & 26 & 24 & 33 \\
\hline Hot carcass weight, $\mathrm{lb}$ & 16 & 31 & 28 & 31 \\
\hline Dressing percentage & 7 & 19 & 21 & 22 \\
\hline Yield grade, calculated & 12 & 29 & 25 & 23 \\
\hline Percentage Choice and greater, \% & 7 & 22 & 24 & 30 \\
\hline Marbling score $^{6}$ & 11 & 29 & 25 & 26 \\
\hline
\end{tabular}

${ }^{1}$ One or more of the test dosages (EST, ET120, and ET200) compared with negative control within each individual study.

${ }^{2}$ Direct comparisons of ET200 vs. ET120 within each individual study.

${ }^{3} \mathrm{EST}=36 \mathrm{mg}$ zeranol, $72 \mathrm{mg}$ zeranol, and $20 \mathrm{mg}$ estradiol benzoate $(\mathrm{EB})+200 \mathrm{mg}$ progesterone.

${ }^{4} \mathrm{ET} 120=24 \mathrm{mg}$ estradiol- $17 \AA+120 \mathrm{mg}$ trenbolone acetate.

${ }^{5}$ ET200 $=20 \mathrm{mg}$ estradiol benzoate $+200 \mathrm{mg}$ trenbolone acetate.

${ }^{6}$ Slight $-00=300$, Small- $00=400$, Modest $-00=500$. 
Table 2. Implant categories for analysis of the effects of estrogenic and combination estrogenic/androgenic implants vs. no implant (Comparison 1) or two combination estrogenic/androgenic implants in feedlot steers (Comparison 2)

\begin{tabular}{ll}
\hline Implant category & Implants or dosages included \\
\hline EST & $36 \mathrm{mg}$ zeranol \\
& $20 \mathrm{mg}$ estradiol benzoate $(\mathrm{EB})+200 \mathrm{mg}$ progesterone \\
& $72 \mathrm{mg}$ zeranol \\
& $24 \mathrm{mg}+120 \mathrm{mg}$ trenbolone acetate $(\mathrm{TBA})$ \\
ET120 & $20 \mathrm{mg}$ estradiol-17ß $+200 \mathrm{mg}$ TBA \\
ET200 & $28 \mathrm{mg}$ EB $+200 \mathrm{mg}$ TBA \\
\end{tabular}

Table 3. Mean effect size of estrogenic and combination estrogenic/androgenic implants compared with no implant (Comparison 1) or two combination estrogenic/androgenic implants in feedlot steers (Comparison 2) determined from meta-analyses

\begin{tabular}{|c|c|c|c|c|c|c|c|c|}
\hline \multirow[b]{2}{*}{ Response variable } & \multirow{2}{*}{$\begin{array}{c}\text { EST, } \\
{\text { ET } 120^{2}}^{2} \\
\text { and } \\
{\text { ET } 200^{3}}\end{array}$} & \multirow{2}{*}{$\begin{array}{c}\text { Across- } \\
\text { treatment } \\
P \text {-value }\end{array}$} & \multicolumn{3}{|c|}{ Compared vs. negative control } & \multirow{2}{*}{$\begin{array}{c}\text { Between- } \\
\text { treatment } \\
P \text {-value }\end{array}$} & \multirow{2}{*}{$\begin{array}{l}\text { ET120² } \\
\text { vs. } \\
\text { ET2003 }\end{array}$} & \multirow[b]{2}{*}{$P$-value } \\
\hline & & & $\mathrm{EST}^{1}$ & $\mathrm{ET} 120^{2}$ & ET2003 & & & \\
\hline Average daily gain, $\mathrm{lb}$ & 0.59 & $<0.01$ & $0.40^{\mathrm{a}}$ & $0.57^{\mathrm{ab}}$ & $0.64^{\mathrm{b}}$ & 0.03 & 0.046 & 0.04 \\
\hline Feed:gain & -0.65 & $<0.01$ & $-0.50^{a}$ & $-0.60^{\mathrm{ab}}$ & $-0.74^{\mathrm{b}}$ & 0.01 & -0.12 & $<0.01$ \\
\hline Dry matter intake, $\mathrm{lb} /$ day & 1.21 & $<0.01$ & 1.12 & 1.12 & 1.23 & 0.92 & -0.02 & 0.64 \\
\hline Hot carcass weight, $\mathrm{lb}$ & 47.1 & $<0.01$ & $30.1^{a}$ & $47.1^{\mathrm{ab}}$ & $53.7^{\mathrm{b}}$ & $<0.01$ & 3.1 & 0.52 \\
\hline Dressing percentage, $\%$ & 0.13 & 0.04 & -0.16 & 0.32 & 0.01 & 0.01 & -0.11 & 0.10 \\
\hline Yield grade, calculated & 0.02 & 0.42 & -0.01 & 0.04 & -0.01 & 0.49 & -0.04 & 0.22 \\
\hline Percentage Choice and greater, $\%$ & -9.8 & $<0.01$ & -9.4 & -9.6 & -11.8 & 0.88 & -5.2 & $<0.01$ \\
\hline Marbling score ${ }^{4}$ & -28 & $<0.01$ & -20.9 & -24.0 & -33.5 & 0.06 & -3.0 & 0.33 \\
\hline
\end{tabular}

${ }^{1} \mathrm{EST}=20 \mathrm{mg}$ estradiol benzoate $+200 \mathrm{mg}$ progesterone, $72 \mathrm{mg}$ zeranol, or $36 \mathrm{mg}$ zeranol.

${ }^{2}$ ET120 $=24$ mg estradiol $-17 ß+120 \mathrm{mg}$ trenbolone acetate.

${ }^{3}$ ET200 $=28 \mathrm{mg}$ estradiol benzoate $+200 \mathrm{mg}$ trenbolone acetate or $20 \mathrm{mg}$ estradiol $-17 \beta+200 \mathrm{mg}$ trenbolone acetate.

${ }^{4}$ Slight $-00=300$, Small- $00=400$, Modest $-00=500$.

a,b,c Means within a row without a common superscript differ $(P<0.05)$. 
Table 4. Results of meta-regression of the effects of ET200 vs. ET120 by days of implant activity $(E T 200=28 \mathrm{mg}$ estradiol benzoate $+200 \mathrm{mg}$ trenbolone acetate or $20 \mathrm{mg}$ estradiol-17 $\beta+200 \mathrm{mg}$ trenbolone acetate; ET120 $=24 \mathrm{mg}$ estradiol-17 $\beta+120 \mathrm{mg}$ trenbolone acetate); only single-implant treatments were included in the metaregression

\begin{tabular}{lccc}
\hline Response variable & Slope & Intercept & $P$-value \\
\hline Average daily gain, lb & -0.0007 & 0.07 & 0.44 \\
Feed:gain & 0.003 & -0.54 & 0.54 \\
Percentage Choice and greater, \% & 0.011 & -19.6 & 0.08 \\
\hline
\end{tabular}

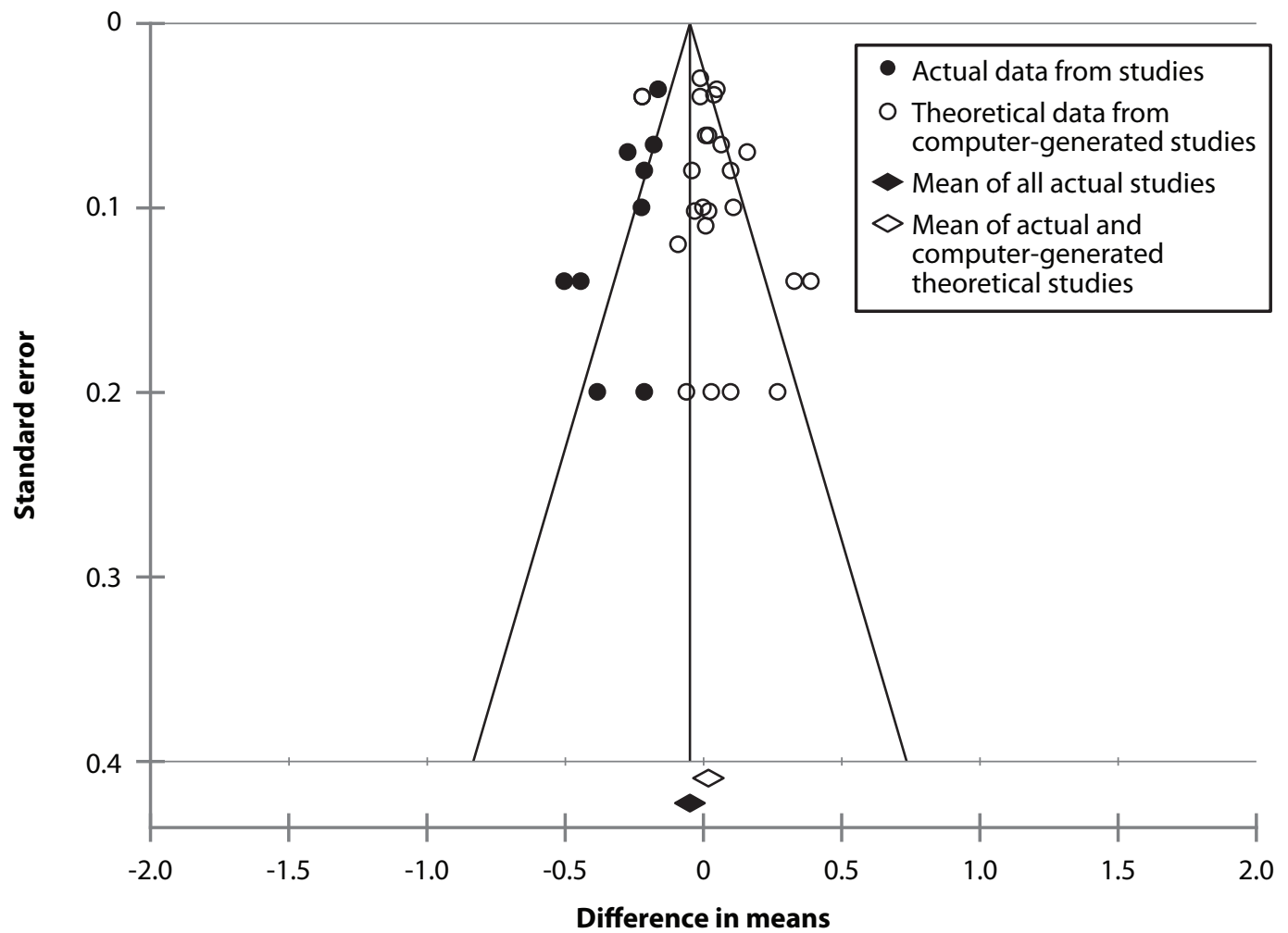

Figure 1. Funnel plot for meta-analysis of average daily gain by implant dosage. 
Fort Dodge Animal Health Syn Ch TR-1 2001 Fort Dodge Animal Health Syn Ch TR-1 2001 Fort Dodge Animal Health Syn Plus TR-4 1994 Fort Dodge Animal Health Syn Plus TR-5 1994 Fort Dodge Animal Health Syn Plus TR-6 1994 Fort Dodge Animal Health Syn Plus TR-7 1994 Fort Dodge Animal Health Syn Plus TR-19 1996 Nichols, W.T. Rev 200 Tech Bulletin 2

Fort Dodge Animal Health Syn Ch TR-2 2002 Fort Dodge Animal Health Syn Plus TR-1 1994 Fort Dodge Animal Health Syn Plus TR-14 1995 Fort Dodge Animal Health Syn Plus TR-18 1995 Fort Dodge Animal Health Syn Plus TR-2 1994 Fort Dodge Animal Health Syn Plus TR-3 1994

U. Milton et al., 1996

Fort Dodge Animal Health Syn Ch TR-3 2003

(2. Haugen et al., UNL Report

J Jimetal., 1996

을 Booker et al., Zeranol

ڤ Jimetal., 1996b

Fort Dodge Animal Health Syn Plus TR-18 1995b Jimetal., 1996c

Bierman et al., 1998

Brandt et al., Revs Tech Bull 18

Fort Dodge Animal Health Syn Plus TR-16 1995 Fort Dodge Animal Health Syn Plus TR-16 1995b

Hermesmeyer et al. 2000 JAS

Hermesmeyer et al. $2000 \mathrm{JASb}$

Hoechst Roussel Vet, 2000A

Hoechst Roussel Vet, 2000B

Hoechst Roussel Vet, 2000C

Hoechst Roussel Vet, 2000D

Drouillard et al., 1999

Fort Dodge Animal Health Syn Plus TR-8 1994

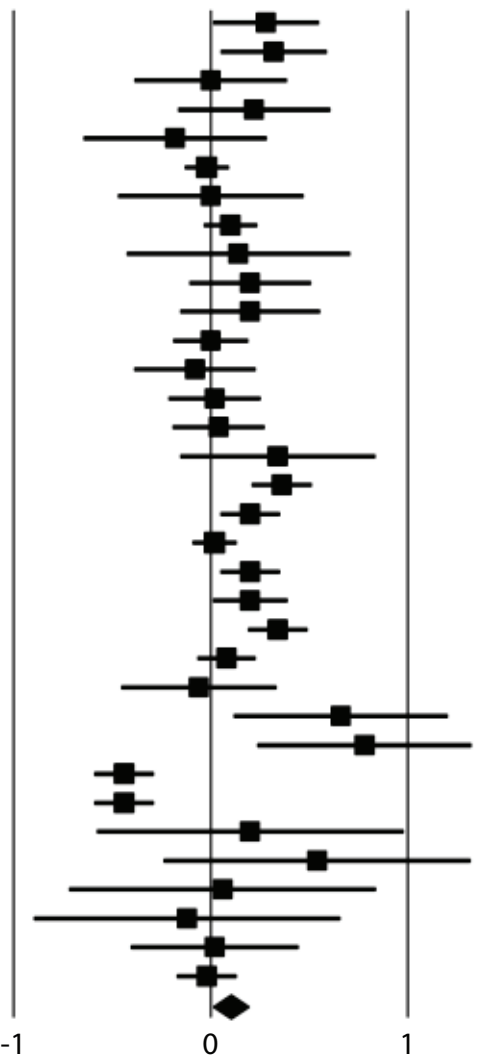

Difference in average daily gain, lb

Figure 2. Forest plot for meta-analysis of average daily gain for ET200 vs. ET120.

Bierman et al., 1998

Brandt et al., Revs Tech Bull 18

Drouillard et al., 1999

Fort Dodge Animal Health Syn Ch TR-1 2001

Fort Dodge Animal Health Syn Ch TR-1 2001

Fort Dodge Animal Health Syn Ch TR-2 2002

Fort Dodge Animal Health Syn Ch TR-3 2003

Fort Dodge Animal Health Syn Plus TR-1 1994

Fort Dodge Animal Health Syn Plus TR-14 1995

Fort Dodge Animal Health Syn Plus TR-16 1995

d Fort Dodge Animal Health Syn Plus TR-16 1995b

E Fort Dodge Animal Health Syn Plus TR-18 1995

E Fort Dodge Animal Health Syn Plus TR-18 1995b

주 Fort Dodge Animal Health Syn Plus TR-19 1996

으 Fort Dodge Animal Health Syn Plus TR-2 1994

ڤ Fort Dodge Animal Health Syn Plus TR-3 1994 Fort Dodge Animal Health Syn Plus TR-4 1994 Fort Dodge Animal Health Syn Plus TR-5 1994 Fort Dodge Animal Health Syn Plus TR-6 1994 Fort Dodge Animal Health Syn Plus TR-7 1994 Fort Dodge Animal Health Syn Plus TR-8 1994

Haugen et al., UNL Report

Hermesmeyer et al. 2000 JAS

Hermesmeyer et al. $2000 \mathrm{JASb}$

Hoechst Roussel Vet, 2000A

Hoechst Roussel Vet, 2000B

Hoechst Roussel Vet, 2000C

Hoechst Roussel Vet, 2000D

Milton et al., 1996

Nichols, W.T. Rev 200 Tech Bulletin 2

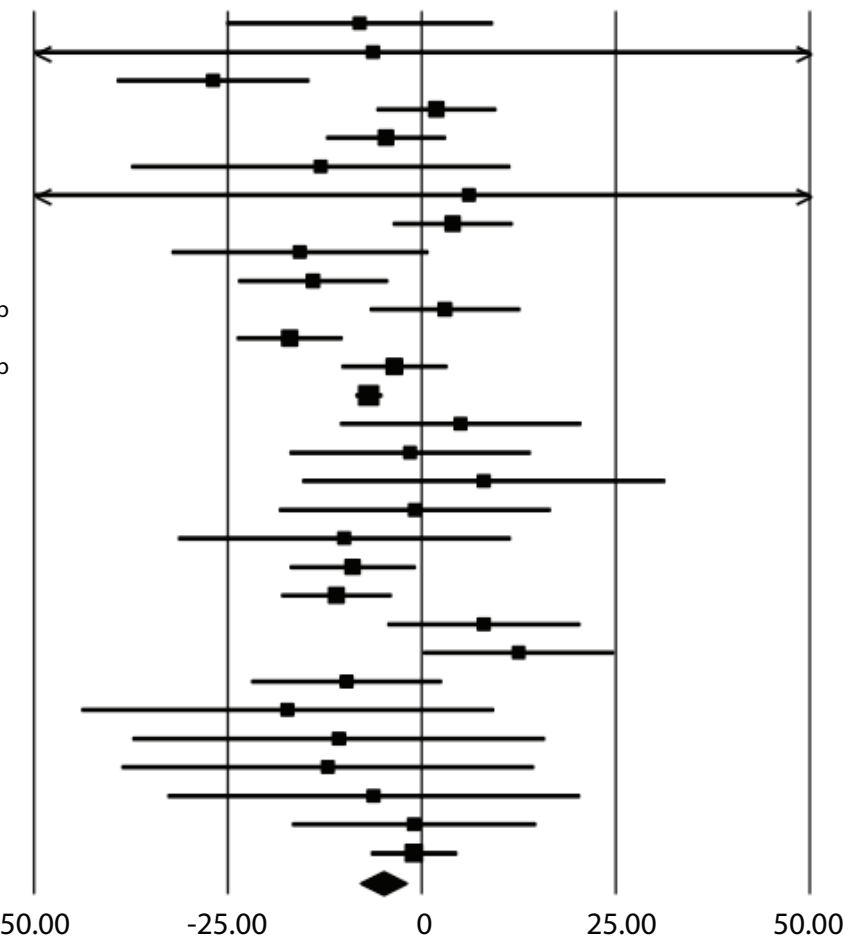

Difference in percentage choice

Figure 3. Forest plot of the effects of ET200 vs. ET120 on percentage of carcasses grading Choice or greater. 


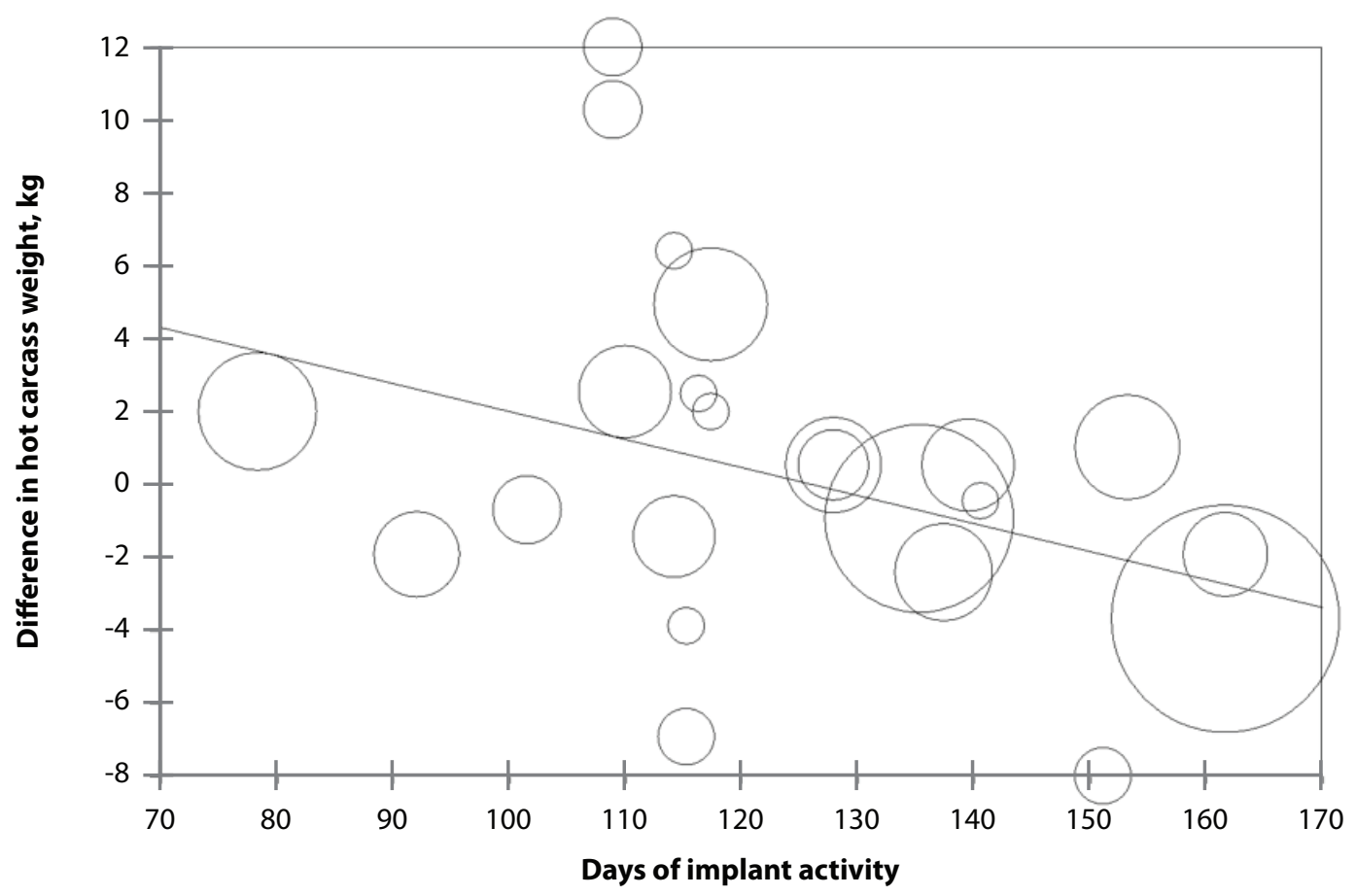

Figure 4. Results of meta-regression of the effects on hot carcass weight of ET200 vs.

ET120 by days of implant activity $($ ET200 $=28 \mathrm{mg}$ estradiol benzoate $+200 \mathrm{mg}$

trenbolone acetate or $20 \mathrm{mg}$ estradiol-17 $\beta+200 \mathrm{mg}$ trenbolone acetate; ET120 $=24 \mathrm{mg}$ estradiol-17ß $+120 \mathrm{mg}$ trenbolone acetate). Only single implant treatments were included in the meta-regression. 